\title{
PENGARUH PENERAPAN SOP (STANDARD OPERATING \\ PROCEDURE) DAN DISIPLIN KERJA TERHADAP \\ KINERJA TENAGA KEPENDIDIKAN DI STIKES SURYA \\ MITRA HUSADA KEDIRI
}

\author{
Yuli Anita Andriani \\ Dra. Nining Purnamaningsih, MM \\ Drs.Gandung Satriyono,ST.MM
}

\begin{abstract}
ABSTRAK
Penelitian ini bertujuan untuk mengetahui seberapa signifikan penerapan SOP (Standard Operating Procedure) dan disiplin kerja terhadap kinerja tenaga kependidikan di STIKes Surya Mitra Husada Kediri. Hal ini dilakukan agar dari pihak STIKes Surya Mitra Husada Kediri dapat melakukan evaluasi guna meningkatkan kinerja karyawan.

Metode pengumpulan data menggunakan wawancara dan kuesioner. Teknik pengambilan sampel dengan menggunakan sampling jenuh. Populasi yang menjadi objek penelitian adalah semua tenaga kependidikan di STIKes Surya Mitra Husada Kediri dengan sampel sebanyak 37 tenaga kependidikan. Analisis yang digunakan uji validitas, uji normalitas dan uji analisis regresi berganda.

Kesimpulan hasil penelitian ini adalah: Berdasarkan dari hasil uji linear berganda diperoleh nilai P Penerapan SOP (Standard Operating Procedure) 0,000 dan P Disiplin 0,000 terhadap kinerja tenaga kependidikan, diartikan penerapan SOP dan Disiplin kerja memberikan pengaruh terhadap kinerja karyawan. Berdasarkan nilai Adjusted R Square 0,976 dapat disimpulkan bahwa penerapan SOP (Standard Operating Procedure) dan disiplin kerja bersama-sama memberikan pengaruh terhadap kinerja karyawan sebesar $97,6 \%$.

Kata Kunci: Standard Operating Procedure, disiplin kerja, dan kinerja tenaga kependidikan.

\section{PENDAHULUAN}

Kinerja kerja yang lebih tinggi dapat dicapai apabila terdapat proses produksi yang lebih baik, peralatan yang modern atau sempurna, atau faktor-faktor lain diharapkan mampu bersama-sama meningkatkan pemanfaatan tenaga kerja secara optimal. Agar pemanfaatan tenaga kerja dapat secara optimal, maka diperlukan perbaikan-perbaikan, motivasi, lingkungan kerja, kondisi fisik pekerja, dan penggajian atau insentif. Faktor yang mempengaruhi tugas pokok guru harus adanya sarana dan
\end{abstract}


prasarana,metode pembelajaran ,pembimbingan dan menanamkan motivasi siswa (Kristanti, 2016).Dengan ada nya peraturan yang dibuat oleh atasan karyawan dalam bekerja selalu disiplin juga dapat termotivasi untuk bekerja lebih giat lagi (Widiningtyas, 2016).

Pada hakekatnya setiap organisasi perusahaan apapun baik organisasi swasta atau pemerintah akan terdapat unsur-unsur yang perlu diarahkan untuk mencapai tujuannya secara efektif dan efisien dengan manajemen yang baik seperti halnya dengan STIKes Surya Mitra Husada Kediri ini di dalam pencapaian tujuannya diperlukan kerjasama antara manusia-manusia yang mengelola organisasi tersebut. Adapun unsurunsur antara lain mesin, material, metode, monet dan pasar, sedangkan manusia dianggap sebagai unsur yang terpenting dari keenam unsur ini layak mendapat perhatian tersendiri.Kecerdasan emosional berpengaruh signifikan terhadap kinerja kontekstual guru (Satriyono, 2018). Kurang sadar dalam kepemilikan usaha dan pemakaian teknologi informasi (Putra, Yudiarto Perdana, heryanto, 2017).

Faktor yang mendorong orang untuk bekerja adalah untuk memenuhi kebutuhan hidupnya. peranan insentif adalah sangat penting karena insentif yang baik dapat memenuhi kebutuhan karyawan. Insentif dapat mendorong karyawan untuk meningkatkan kinerja kerja. Insentif dapat digunakan untuk memuaskan kebutuhan psikologis dan sosial, maka tidak heran kalau banyak karyawan menginginkan insentif tinggi dari pekerjaannya. Agar tujuan organisasi suatu perusahaan dapat tercapai, maka harus ada kerjasama yang baik antara pemimpin dan bawahan disertai adanya kegairahan kerja yang tinggi. Salah satu caranya adalah pemberian rangsangan atau dorongan yang berupa motivasi finansial. Dengan demikian peranan manusia dalam usaha untuk mencapai tujuan sangat menentukan. Pemberian motivasi finansial yang sesuai pada karyawan diharapkan mampu memberi dorongan serta mempengaruhi karyawan untuk meningkatkan semangat dan gairah kerja .sehingga kinerja kerja lebih baik.

Seorang pimpinan mempunyai kebijakan sendiri untuk mengatur anak buahnya agar disiplin dengan baik karena ada hubungan yang sangat diperlukan untuk memberikan bimbingan dan penyuluhan bagi karyawan dalam menciptakan tata tertib yang baik di perusahaan.

\section{TINJAUAN PUSTAKA}




\section{Landasan Teori}

\section{SOP (Standard Operating Procedure)}

SOP (Standard Operating Procedure) yaitu merupakan tahap kegiatan untuk menyelesaikan suatu aktivitas, atau metode langkah demi langkah secara pasti dalam memecahkan suatu masalah (Fatimah, 2015). Untuk mencapai tujuan dan sasaran yang telah ditetapkan, maka prosedur ini harus memiliki standar kerja sebagai dasarnya.

Tujuan SOP pada dasarnya, untuk memberikan pedoman kerja agar kegiatan perusahaan dapat terkontrol. Tujuannya menurut (Fatimah, 2015):

1. Menjaga konsistensi kerja setiap karyawan.

2. Memperjelas alur tugas, wewenang, serta tanggung jawab setiap unit kerja.

3. Mempermudah proses pemberian tugas serta tanggung jawab kepada karyawan yang menjalankannya.

4. Mempermudah proses monitoring dan fungsi kontrol dari setiap proses kerja.

5. Mempermudah proses pemahaman staf secara sistematis dan menyeluruh.

\section{Disiplin Kerja}

Pengertian Disiplin

Di dalam kehidupan sehari-hari, di mana pun manusia berada, dibutuhkan peraturan-peraturan dan ketentuan ketentuan yang akan mengatur dan membatasi setiap kegiatan dan perilakunya. Namun peraturan-peraturan tersebut tidak akan ada artinya bila tidak disertai sanksi bagi para pelanggarnya.

Singodimedjo dalam Sutrisno (2002), mengatakan disiplin adalah sikap seseorang untuk mematuhi dan menaati norma-norma peraturan yang diberlakukan didalam bekerja. Disiplin karyawan yang baik akan mempercepat tujuan perusahaan, sedangkan disiplin yang merosot akan menjadi penghalang dan memperlambat pencapaian tujuan perusahaan. Sedangkan menurut Siagian dalam Sutrisno (2002), Disiplin berarti tindakan yang diambil dengan penyeliaan untuk mengoreksi perilaku dan sikap yang salah.

\section{Kinerja Karyawan}

Kinerja yaitu melaksanakan segala sesuatu pekerjaan yang menjadi tanggung jawab seseorang, maka yang menjadi tolok ukur adalah kinerja. Sehubungan dengan 
kinerja, banyak batasan yang diberikan oleh para ahli mengenai istilah ini. Secara prinsip para ahli setuju bahwa kinerja mengarah pada suatu upaya dalam rangka mencapai prestasi kerja yang lebih baik.

Kinerja adalah ukuran dari suatu hasil. Hasil dari suatu pekerjaan dapat berupa barang atau jasa dan kinerja seseorang dapat dilihat dari sesuatu keberhasilan seseorang. Jika jasa atau barang dapat dihasilkan segala sesuatunya pasti dapat diharapkan berarti kinerja baik sebaliknya jika jasa atau barang dihasilkan buruk tidak sesuai dengan apa yang diharapkan, maka dapat dikatakan kinerjanya buruk (Robbins dalam Sudaryono, 2004).

\section{Kerangka Berpikir}

\section{Gambar 1 : Kerangka berfikir}

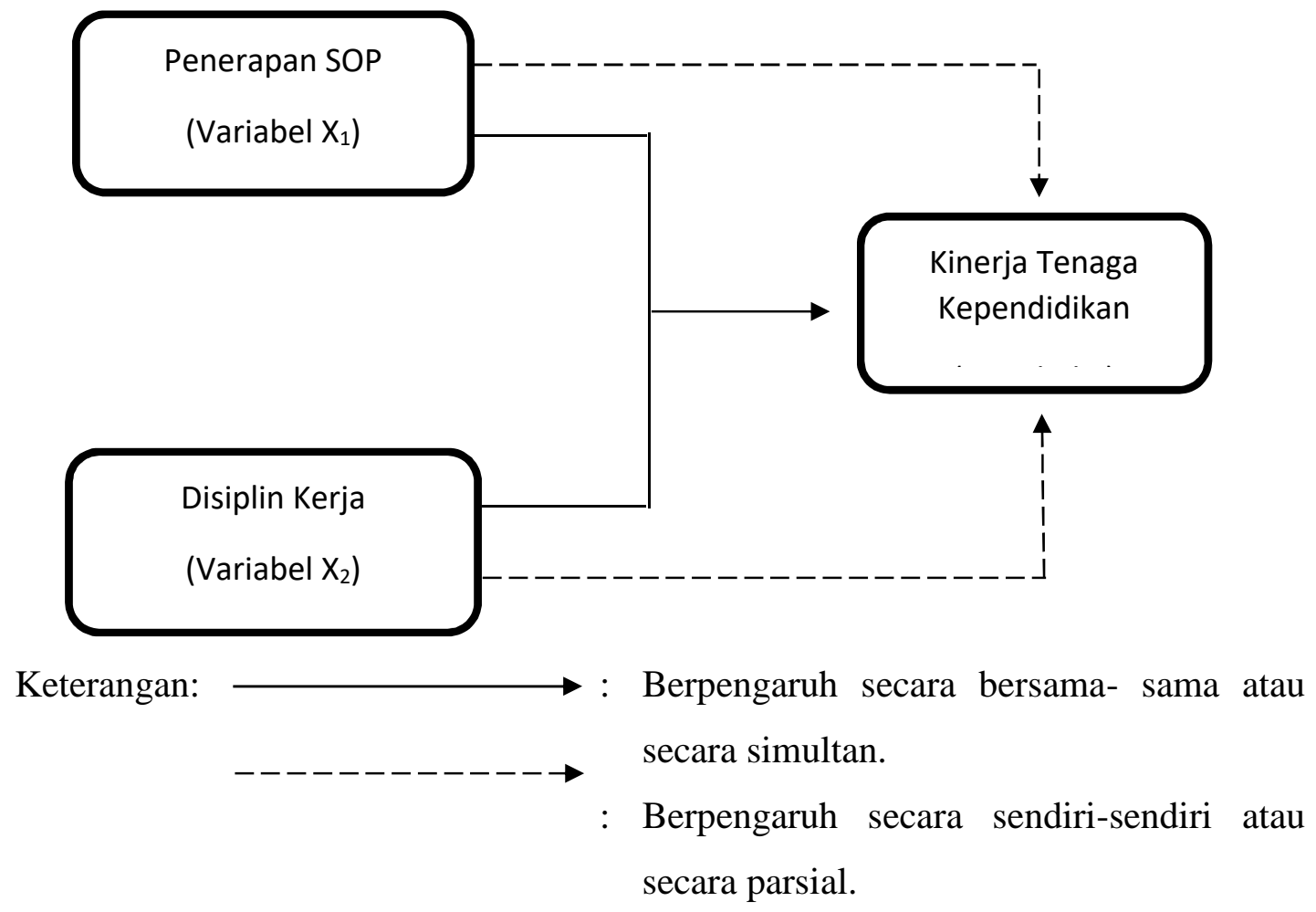

\section{Hipotesis}

Hipotesis adalah suatu pernyataan yang menunjukkan dugaan nilai dalam satu variabel atau lebih (Sugiyono, 2013). Dari kerangka konsep di atas, maka hipotesis dalam penelitian ini dirumuskan sebagai berikut: 
1. Diduga ada pengaruh penerapan SOP terhadap kinerja Tenaga Kependidikan di STIKes Surya Mitra Husada Kediri.

2. Diduga ada pengaruh disiplin kerja terhadap kinerja Tenaga Kependidikan di STIKes Surya Mitra Husada Kediri.

3. Diduga variabel SOP dan disiplin kerja secara simultan akan berpengaruh terhadap kinerja Tenaga Kependidikan di STIKes Surya Mitra Husada Kediri.

\section{METODE PENELITIAN}

\section{Populasi dan Sampel Penelitian}

Populasi adalah sekelompok orang, peristiwa, atau benda yang menjadi pusat perhatian untuk diteliti. Adapun yang menjadi populasi dalam penelitian ini adalah data jumlah karyawan yang bekerja pada TIKes Surya Mitra Husada Kediri yaitu 37 Tenaga Kependidikan.

Sampel adalah anggota populasi yang terpilih untuk diambil atau diselidiki. Maka yang menjadi sampel dalam penelitian ini adalah semua data jumlah Tenaga Kependidikan yang bekerja di STIKes Surya Mitra Husada Kediri yaitu 37 Tenaga Kependidikan

\section{Variabel Penelitian}

Variabel merupakan gejala yang menjadi fokus peneliti untuk diamati variabel itu sebagai atribut sekelompok orang atau objek yang mempunyai variasi antara satu dengan lainnya dalam kelompok itu (Sugiyono, 2015). Menurut (Ghozali,2011), dalam hubungan sebab akibat antara satu variabel dengan variabel yang lain, variabel-variabel penelitian dapat dibedakan menjadi:

1. Variabel Bebas

Variabel bebas (independen) adalah variabel yang mempengaruhi variabel terikat (dependen), baik pengaruh positif maupun negative (Ghozali, 2011). Variabel independen yang digunakan dalam penelitian ini adalah SOP (Standard Operating Procedure) (X1), Disiplin kerja (X2).

2. Variabel Terikat 
Variabel terikat (dependen) adalah variabel yang dipengaruhi oleh variabel bebas (independen). Variabel terikat yang digunakan dalam penelitian ini adalah Kinerja (Y).

\section{Metode Pengumpulan Data}

Adapun teknik pengumpulan data yang penulis gunakan menurut (Sugiyono, 2013) adalah sebagai berikut:

1. Observasi, cara pengumpulan data yang dilakukan dengan cara melakukan pengamatan langsung pada obyek penelitian serta melakukan pencatatan secara sistematis mengenai hal-hal yang diteliti.

2. Kuesioner, pengumpulan data dengan usaha mendapatkan keterangan-keterangan dan pendirian seseorang secara tertulis dengan menyerahkan lembar pertanyaan untuk diisi oleh subyek yang bersangkutan.

3. Dokumentasi, merupakan teknik pengumpulan data dengan cara mencari dan mengumpulkan dokumen pada lokasi penlitian. Yang menjadi dokumen dalam penelitian ini adalah data mengenai latar belakang perusahaan, dan data jumlah karyawan.

\section{Metode Analisis Data}

Adapun teknik analisis yang digunakan dalam penelitian ini antara lain sebagai berikut:

\section{Validitas dan Reliabilitas}

Validitas menunjukkan sejauh mana alat itu mengukur apa yang ingin diukur. membandingkan antara hasil nilai $r$ dengan tabel nilai perhitungan nilai kritis $r$ pada taraf signifikan. Tingkat kepercayaan yang digunakan dalam perhitungan ini adalah $99 \%$ dan $95 \%$, apabila dalam pengujian diperoleh hasilsama dengan taraf signifikan $(\alpha$ $=0,01$ dan $\alpha=0,05)$ maka terdapat hubungan antar variabel, tetapi apabila yang terjadi sebaliknya maka tidak terdapat hubungan antar variabel. 
Apabila nilai $r$ hitung diperoleh berada diatas nilai kritis berarti alat ukur yang digunakan telah valid. Reliabilitas dapat diukur dari koefisien korelasi antara percobaan pertama dengan berikutnya, bila koefisien korelasi positif dan signifikan maka instrument tersebut sudah dinyatakan reliable (Arikunto, 2010)

\section{Metode Analisis Regresi}

Regresi adalau suatu proses melakukan estimasi untuk memperoleh hubungan fungsional antara variabel acak. Analisis yang digunakan untuk peramalan masa yang akan datang, apabila akan diadakan perubahan pada variabel bebas. Adapun rumus Regresinya adalah sebagai berikut:

$$
\mathrm{Y}=\mathrm{a}+\mathrm{b}_{1} \mathrm{X}_{1}+\mathrm{b}_{2} \mathrm{X}_{2}+\mathrm{b}_{3} \mathrm{X}_{3}
$$

Di mana:

$\mathrm{Y}=$ variabel bebas

$\mathrm{a}=$ bilangan konstanta

$\mathrm{b}=$ koefisien regresi

$\mathrm{x}=$ variabel bebas

\section{Uji Normalitas}

Penelitian ini menguji adakah pengaruh penerapan SOP (standard operating procedure) dan disipli kerja terhadap kinerja tenaga kependidikan di STIKes Surya Mitra Husada Kediri. Oleh karena itu uji normalitas perlu dilakukan untuk menentukan alat uji hipotesis yang akan digunakan, yaitu uji statistic parametric atau uji statistic non parametrik. Pengujian nomalitas akan dilakukan dengan menggunakan uji KolmogorovSmirnov (Ghozali 2006)

\section{HASIL DAN PEMBAHASAN}

\section{Uji Validitas dan Reliabilitas}

Tabel Hasil Uji Validitas dan Reliabilitas

Kuesioner Penerapan SOP (Standard Operating Procedure)

\begin{tabular}{|c|c|}
\hline No Soal & R Hitung \\
\hline 1 & 0,813 \\
\hline
\end{tabular}




\begin{tabular}{|c|c|}
\hline 2 & 0,742 \\
\hline 3 & 0,739 \\
\hline 4 & 0,635 \\
\hline 5 & 0,674 \\
\hline
\end{tabular}

b. Hasil Uji Validitas dengan menggunakan uji person, dari 5 soal didapatkan nilai diatas $\mathrm{R}$ hitung lebih besar dari $\mathrm{R}$ table $(0,349)$ dengan jumlah sampel 32 responden.

c. Uji reliabilitas dengan menggunakan uji alpha Chronbach diperoleh nilai 0,782 diartikan nilai reliabilitasnya dalam kategori baik.

Tabel Hasil Uji Validitas dan Reliabilitas

Kuesioner Kedisiplinan Kerja

\begin{tabular}{|c|c|}
\hline No Soal & R Hitung \\
\hline 1 & 0,793 \\
\hline 2 & 0,788 \\
\hline 3 & 0,795 \\
\hline 4 & 0,667 \\
\hline 5 & 0,663 \\
\hline
\end{tabular}

1. Hasil Uji Validitas dengan menggunakan uji person, dari 5 soal didapatkan nilai diatas R Hitung lebih besar dari R Tabel 0,349 dengan jumlah sampel 32 responden. 
2. Uji reliabilitas dengan menggunakan uji alpha Chronbach diperoleh nilai 0,791 diartikan nilai reliabilitasnya pada kategori baik.

Tabel Hasil Uji Validitas dan Reliabilitas

Kuesioner Kinerja Karyawan

\begin{tabular}{|c|c|}
\hline No Soal & R Hitung \\
\hline 1 & 0,723 \\
\hline 2 & 0,784 \\
\hline 3 & 0,690 \\
\hline 4 & 0,731 \\
\hline 5 & 0,715 \\
\hline
\end{tabular}

1. Hasil Uji Validitas dengan menggunakan uji person, dari 5 soal didapatkan nilai diatas R Hitung lebih besar dari R Tabel 0,349 dengan jumlah sampel 32 responden.

2. Uji reliabilitas dengan menggunakan uji alpha Chronbach diperoleh nilai 0,791 diartikan nilai reliabilitasnya pada kategori baik.

\section{Uji Regresi Linier Berganda}

Dalam analisa linier regresi ini digunakan untuk mengetahui pengaruh masingmasing variabel independen yang terdiri dari SOP (Standard Operating Procedure) $\left(\mathrm{X}_{1}\right)$ dan Disiplin Kerja $\left(\mathrm{X}_{2}\right)$ terhadap variabel dependen Kinerja Karyawan (Y) di STIKes Surya Mitra Husada Kediri.

Tabel : Hasil Uji Regresi Linnear Berganda

\section{Coefficients $^{\mathbf{a}}$}




\begin{tabular}{|c|c|c|c|c|c|}
\hline \multirow[b]{2}{*}{ Model } & \multicolumn{2}{|c|}{$\begin{array}{l}\text { Unstandardized } \\
\text { Coefficients }\end{array}$} & \multirow{2}{*}{$\begin{array}{l}\text { Standardized } \\
\text { Coefficients } \\
\text { Beta }\end{array}$} & \multirow[b]{2}{*}{$\mathrm{t}$} & \multirow[b]{2}{*}{ Sig. } \\
\hline & B & Std. Error & & & \\
\hline (Constant) &,- 646 & ,607 & & $-1,065$ & ,295 \\
\hline $\mathrm{X}_{1}$ & ,610 &, 082 & ,603 & 7,405 &, 000 \\
\hline$X_{2}$ &, 427 &, 087 & ,400 & 4,913 & ,000 \\
\hline
\end{tabular}

a. Dependent Variable: Y

Sumber: Data Diolah (2018).

Berdasarkan hasil uji regresi linier pada tabel di atas, diperoleh nilai $\mathrm{P}$ Penerapan SOP (Standard Operating Procedure) 0,000 dan P Disiplin 0,000 terhadap kinerja karyawan, diartikan penerapan SOP (Standard Operating Procedure) dan Disiplin Kerja memberikan pengaruh terhadap kinerja tenaga kependidikan. Berdasarkan nilai Adjusted R Squere 0,976 dapat disimpulkan bahwa penerapan SOP dan disiplin kerja bersama sama memberikan pengaruh terhadap kinerja Tenaga Kependidikan sebesar 97,6\%.

\section{Uji Normalitas}

Tabel Hasil Uji Normalitas

\begin{tabular}{|l|r|r|r|r|r|r|}
\hline & \multicolumn{3}{|c|}{ Kolmogorov-Smirnov $^{\text {a }}$} & \multicolumn{2}{c|}{ Shapiro-Wilk } \\
\cline { 2 - 7 } & Statisti & & & & & \\
\hline Penerapan_SOP &, 149 & 34 &, 055 &, 942 & 34 &, 071 \\
\hline disiplin_kerja &, 135 & 34 &, 122 &, 963 & 34 &, 306 \\
\hline
\end{tabular}




\begin{tabular}{|l|l|l|l|l|l|l|}
\hline kinerja_karyawan &, 144 & 34 &, 072 &, 943 & 34 &, 075 \\
\hline
\end{tabular}

a. Lilliefors Significance Correction

Sumber: Data Diolah (2018).

Dari hasil uji normalitas dengan menggunakan uji Kolmogorov-Smirnov diperoleh nilai P Penerapan SOP (Standard Operating Procedure) 0,055, P Disiplin Kerja 0,122 dan P Kinerja Karyawan 0,072 dimana lebih besar dari 0,05 yang artinya data berdistribusi normal

\section{KESIMPULAN DAN SARAN}

\section{Kesimpulan}

Setelah melakukan analisis data dan pembahasan tentang pengaruh penerapan SOP (Standard Operating Procedure) dan disiplin kerja terhadap kinerja karyawan pada STIKes Surya Mitra Husada Kediri, maka dapat diambil kesimpulan sebagai berikut:

a. Dari hasil uji normalitas dengan menggunakan uji Kolmogorov-Smirnov diperoleh nilai P Penerapan SOP (Standard Operating Procedure) 0,055, P Disiplin Kerja 0,122 dan P kinerja Tenaga Kependidikan 0,722 dimana lebih besar dari alpha 0,05 yang artinya data berdistribusi normal.

b. Berdasarkan hasil uji linear berganda diperoleh nilai P Penerapan SOP (Standard Operating Procedure) 0,000 dan P Disiplin 0,000 terhadap kinerja karyawan, diartikan penerapan SOP (standard operating Procedure) dan disiplin kerja memberikan pengaruh terhadap kinerja karyawan. Berdasarkan nilai Adjust $\mathrm{R}$ Square 0,976, dapat disimpulkan bahwa penerapan SOP (Standard Operating Procedure) dan disiplin kerja bersama sama memberikan pengaruh terhadap kinerja karyawan sebesar $97,6 \%$

\section{Saran}

Berdasarkan kesimpulan diatas, maka penulis dapat memberikan saran sebagai berikut:

a. Pihak manajemen STIKes Surya Mitra Husada Kediri diharapkan mampu mempertahankan dan meningkatkan lagi penerapan SOP (Standard Operating Procedure) untuk kemajuan perusahaan. 
b. Pihak manajemen STIKes Surya Mitra Husada Kediri diharapkan mampu mempertahankan dan meningkatkan lagi penerapan disiplin kerja, mengingat kinerja tenaga kependidikan menjadi faktor penting dan sangat menentukan hasil kerja.

c. Diharapkan untuk peneliti selanjutnya dapat melengkapi kekurangan penulis pada penelitian ini. Serta diharapkan penelitian yang akan datang dapat lebih sempurna dibanding penelitian ini.

\section{DAFTAR PUSTAKA}

Arikunto. 2016. Prosedur Penelitian: Suatu Pendekatan Praktek. Rineka Cipta, Jakarta.

As ad, Muhammad. 2015. Psikologi Industri. Liberty, Yogyakarta.

Kristanti, D. (2016). Faktor-faktor Yang Mempengaruhi Pelaksanaan Tugas Pokok Guru (Studi Pada MA AL Muttaquun Wates). Ekonika, 1(1), 13-25. https://doi.org/http://dx.doi.org/10.30737/ekonika.v1i1.2

Putra, Yudiarto Perdana, heryanto, B. (2017). PEMETAAN KEPEMILIKAN BADAN HUKUM DAN TINGKAT PENGGUNAAN TEKNOLOGI INFORMASI PADA UMKM ( Studi Pada Kelurahan Pojok Kecamatan Mojoroto - Kota Kediri ). EKONIKA, 2(2), 183-197. https://doi.org/http://dx.doi.org/10.30737/ekonika.v2i2.44

Satriyono, G. (2018). Pengaruh Kecerdasan Emosial terhadap Kinerja Guru di SMP Negeri 4 Kediri. Ekonika, 3(1), 31-46. https://doi.org/http://dx.doi.org/10.30737/ekonika.v3i1.104

Widiningtyas, R. (2016). Pengaruh Disiplin Kerja Dan Motivasi Kerja Terhadap Kinerja Karyawan. Pengaruh Disiplin Kerja Dan Motivasi Kerja Terhadap Kinerja Karyawan. Retrieved from https://www.google.co.id/url?sa=t\&rct=j\&q=\&esrc=s\&source=web\&cd=1\&cad=rj a\&uact $=8 \&$ ved $=0$ ahUKEwjxxPuS-vYAhXLrY8KHSzfDdAQFggoMAA\&url=http\%3A\%2F\%2Feprints.uny.ac.id\%2 F39125\%2F1\%2FRikaWidyaningtyas_11408144063.pdf\&usg=AOvVaw1W0v1J5 iFrQ0xqtlb71Axz

Dwi, Priyatno. 2012. 5 Jam Belajar Olah Data dengan SPSS 17. Andi, Yogyakarta.

Fatimah Nur, Endah. 2015. Strategi pintar menyusun SOP (Standard Operating

Procedure). Penerbit Pustaka Baru Press, Yogyakarta.

George R, Terry. 2013. Prinsip-prinsip Management. PT. Bumi Aksara, Jakarta.

Ghozali, Imam. 2006. Statistik Non-parametrik. Teori dan aplikasi dengan program SPSS. Universitas Diponegoro, Semarang. 
Maryati, MC. 2012. Manajemen Perkantoran Efektif. UUP STIM YKPN, Yogyakarta.

Prawirosentono, Suyadi. 2012. Manajemen Sumberdaya Manusia: Kebijakan Kinerja Karyawan Kiat Membangun Organisasi Kompetitif Menjelang Perdagangan Bebas Dunia. BPFE, Yogyakarta.

Priyatno, Duwi. 2013. Analisis korelasi, regresi dan mulvariate dengan SPSS. Penerbit Gava Media, Yogyakarta.

Sedarmayanti. 2012. Sumber daya Manusia dan Produktivitas Kerja. CV. Mandar Maju, Bandung.

Sekaran, Uma. 2013. Metode Penelitian Untuk Bisnis. Salemba Empat, Jakarta.

Siagian, Sondang P. 2012. Sumber Daya Manajemen Manusia. Bumi Aksara, Jakarta.

Singodimedjo, Markum. 2010. Manajemen Sumber Daya Manusia. SMMAS, Surabaya.

Stephen P, Robbins. 2014. Teori Organisasi: Struktur, Desain dan Aplikasi. Arcan, Jakarta.

Stephen P, Robbins. 2016. Perilaku Organisasi. PT. Indeks, Jakarta.

Sudaryono. 2017. Pengantar Manajemen. CAPS. Center for Academic Publishing Service, Yogyakarta. 